\title{
Pulmonary Vascular Platform Models the Effects of Flow and Pressure on Endothelial Dysfunction in BMPR2 Associated Pulmonary Arterial Hypertension
}

\author{
Reid W. D'Amico ${ }^{1, *}$, Shannon Faley ${ }^{2}$, Ha-na Shim ${ }^{3}$, Joanna R. Prosser ${ }^{3}$, Vineet Agrawal ${ }^{3}$ (D), \\ Leon M. Bellan 1,2*(D) and James D. West ${ }^{1,3, *}$ \\ 1 Department of Biomedical Engineering, Vanderbilt University, Nashville, TN 37232, USA \\ 2 Department of Mechanical Engineering, Vanderbilt University, Nashville, TN 37232, USA; \\ shannon.faley@vanderbilt.edu \\ 3 Division of Allergy, Pulmonary, and Critical Care Medicine, Vanderbilt University Medical Center, \\ Nashville, TN 37232, USA; ha-na.shim@vumc.org (H.-n.S.); joanna.johnson@vumc.org (J.R.P.); \\ vineet.agrawal@vumc.org (V.A.) \\ * Correspondence: reid.damico@vanderbilt.edu (R.W.D.); leon.bellan@vanderbilt.edu (L.M.B.); \\ j.west@vanderbilt.edu (J.D.W.); Tel.: +1-615-343-0895 (L.M.B.)
}

Received: 30 July 2018; Accepted: 22 August 2018; Published: 29 August 2018

\begin{abstract}
Endothelial dysfunction is a known consequence of bone morphogenetic protein type II receptor (BMPR2) mutations seen in pulmonary arterial hypertension (PAH). However, standard 2D cell culture models fail to mimic the mechanical environment seen in the pulmonary vasculature. Hydrogels have emerged as promising platforms for 3D disease modeling due to their tunable physical and biochemical properties. In order to recreate the mechanical stimuli seen in the pulmonary vasculature, we have created a novel 3D hydrogel-based pulmonary vasculature model ("artificial arteriole") that reproduces the pulsatile flow rates and pressures seen in the human lung. Using this platform, we studied both Bmpr ${ }^{\mathrm{R} 899 \mathrm{X}}$ and WT endothelial cells to better understand how the addition of oscillatory flow and physiological pressure influenced gene expression, cell morphology, and cell permeability. The addition of oscillatory flow and pressure resulted in several gene expression changes in both WT and Bmpr $2^{\mathrm{R} 899 \mathrm{X}}$ cells. However, for many pathways with relevance to PAH etiology, Bmpr $2^{\mathrm{R} 899 \mathrm{X}}$ cells responded differently when compared to the WT cells. Bmpr ${ }^{\mathrm{R} 899 \mathrm{X}}$ cells were also found not to elongate in the direction of flow, and instead remained stagnant in morphology despite mechanical stimuli. The increased permeability of the Bmpr ${ }^{\mathrm{R} 899 \mathrm{X}}$ layer was successfully reproduced in our artificial arteriole, with the addition of flow and pressure not leading to significant changes in permeability. Our artificial arteriole is the first to model many mechanical properties seen in the lung. Its tunability enables several new opportunities to study the endothelium in pulmonary vascular disease with increased control over environmental parameters.
\end{abstract}

Keywords: pulmonary arterial hypertension; endothelial dysfunction; disease modeling

\section{Introduction}

Pulmonary arterial hypertension $(\mathrm{PAH})$ is a disease characterized by the progressive occlusion of small pulmonary arteries through the proliferation of vascular cells. This leads to an increase in pulmonary vascular resistance, and eventually results in death from right heart failure [1-7]. The heritable form of PAH due to bone morphogenetic protein type II receptor (BMPR2) mutations leads to significant alterations in transcriptome-wide expressions in both human lung and cells cultured in flasks [8-10]. Specifically, studies have found that the deregulation of the Ras/Rho GTPase pathway plays a large role in the cytoskeletal defects seen in PAH $[8,10-14]$. The cytoskeletal 
defects and endothelial dysfunction are widely observed in PAH patients, and have been linked to $B M P R 2$-associated disease [8]. While it is known that endothelial cells are sensitive and reactive to mechanical forces like shear $[15,16]$, the intersection of BMPR2-associated PAH and mechanical properties of the pulmonary vasculature is still largely unknown.

Investigators have been interested in the effects of mechanical stimuli (e.g., pressure and flow) on the endothelium for decades. Surgical trials in animals in the 1960s showed that alleviating pressure and flow alone largely resolved pulmonary vascular remodeling [17-21]. However, this level of fine control of local vascular mechanics is impractical when studying vascular disease in humans and is incapable of revealing important molecular consequences of pulmonary vascular remodeling. More recently, there has been a growing interest in examining some of these mechanical factors in the context of pulmonary hypertension, with recent papers investigating the effects of stiffness, flow, and stretch on pulmonary vascular cells [22-24]. There is substantial evidence that changes in the mechanical properties of the pulmonary vasculature are the critical determinants of disease progression. These mechanical stimuli override the effects of initiating events and result in common molecular and physiological pathology by the time the disease has become clinically relevant, regardless of initial etiology [25-28].

The aberrant gene expression and cytoskeletal architecture in BMPR2 mutant pulmonary endothelial cells may contribute to endothelial dysfunction [8]. This endothelial dysfunction can manifest in a number of ways, including abnormal barrier function, deregulated cytoskeletal assembly, and improper cytoskeletal organization. However, all in vitro studies have examined cells in stagnant dishes and no studies have probed the effect of mechanical stimuli on driving the endothelial dysfunction in PAH. To date, it has not been possible to study the effects of pressure and flow in a relevant 3D model, as none of the earlier platforms used were capable of independently controlling these critical parameters.

To overcome this limitation, we have created a new artificial arteriole cell culture platform that comprises a hydrogel-based extracellular matrix, controlled perfusion system, and fluidic network. Pressures, shear stresses, and pulsatile flow are controlled by a microcontroller-operated system of pumps and channels, and each parameter may be set to a biologically-relevant value. Thus, we are able to mimic, in a 3D cell culture platform, the mechanical stimuli that are seen in the vessels in the lung.

This artificial arteriole platform presents an opportunity to study how oscillatory flow leads to differences in gene expression, morphology, and barrier function in Bmpr $2^{\mathrm{R} 899 \mathrm{X}}$ and wild type (WT) murine pulmonary microvascular endothelial cells (MPMVECs) and thus provides a more biomimetic environment to study PAH in vitro.

\section{Results}

\subsection{Engineering an Artificial Arteriole}

A peristaltic pump and a microcontroller circuit were designed to enable pulsatile flow and tunable mechanical parameters within the model. The circuit was situated outside an incubator and was designed to control the peristaltic pump from within the incubator. The peristaltic pump was engineered to perfuse an artificial endothelium within a closed dish.

The artificial endothelium channel was made of 10\% gelatin crosslinked with 10\% MTG in a 10:1 ratio. Young's modulus was measured to be $131.89 \mathrm{~Pa} \pm 13.07 \mathrm{~Pa}$ by an Instron 5944 (Norwood, MA, USA) equipped with $10 \mathrm{kN}$ compression. A schematic depicting the manufacturing of the artificial endothelium channel can be seen in Figure 1. 


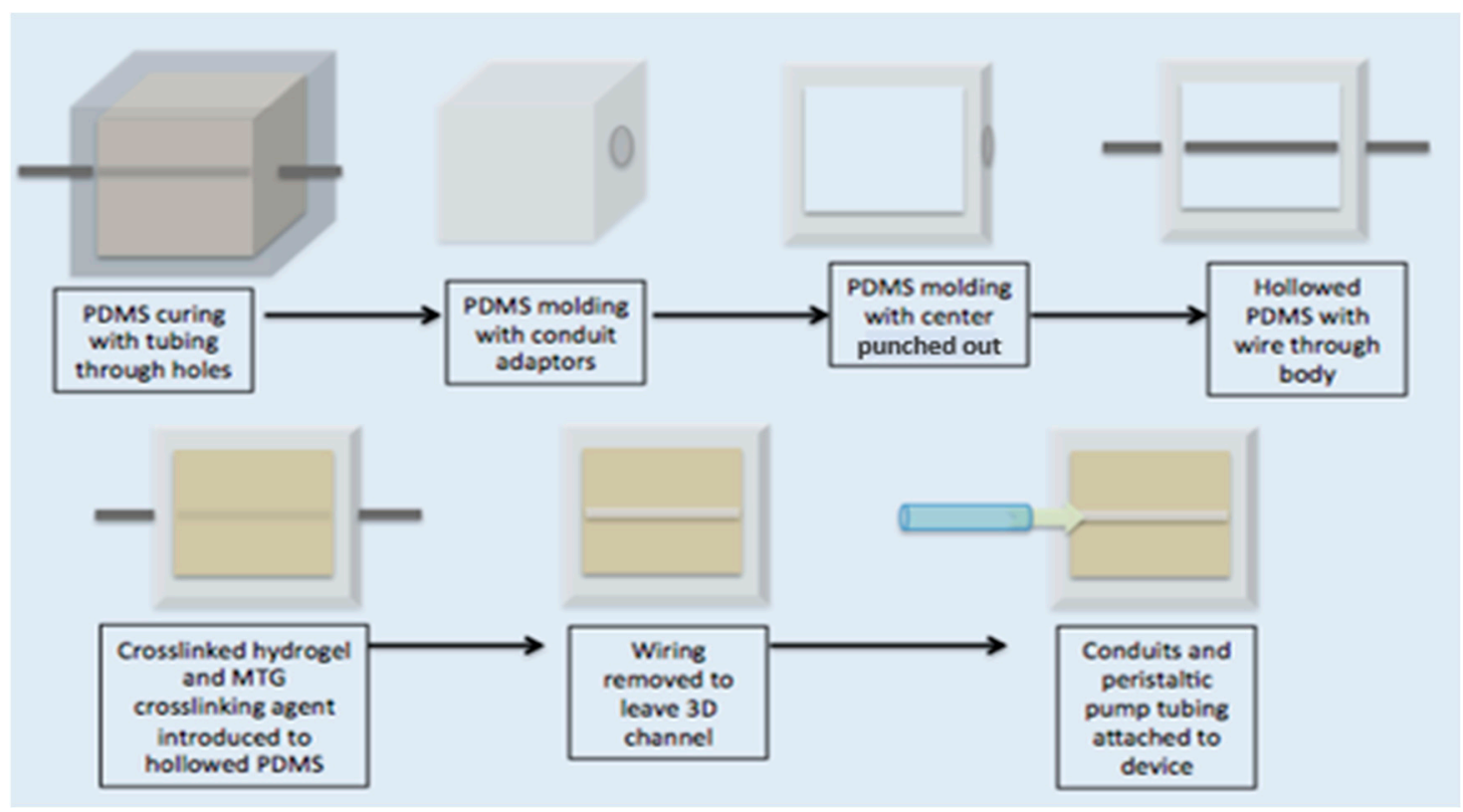

Figure 1. Schematic of artificial arteriole channel assembly. The artificial arteriole channel and PDMS mold construct was created through a series of molding and casting steps depicted above. The top row illustrates how to manufacture the PDMS mold and the bottom steps illustrate how to create the artificial arteriole construct.

By manipulating the vessel diameter, and conduit tubing diameter and length, we were able to change both the shear stresses and pressure waveforms within the artificial endothelium channel. The inner-channel pressure was successfully characterized within the center of the channel by a catheter inserted prior to each flow experiment.

While it was possible to generate several different pressure waveforms in the channel using our perfusion system, the waveform that was similar to the pressures in human pulmonary arterioles was chosen for experimentation. Devices designed to replicate the pulmonary arterioles generated stable pressure values, with a standard deviation of $0.68 \mathrm{mmHg}$. The platform chosen had a channel diameter of $900 \mu \mathrm{m}$ and perfusion conduit tubing with a diameter of $1.5 \mathrm{~mm}$.

The fluidic resistance provided by this channel geometry facilitated the production of an oscillatory pressure wave with a pressure difference of about $9 \mathrm{mmHg}$ that was sustained throughout the course of each experiment (Figure 2). Poiseuille's law was used to estimate a shear stress of $98 \mathrm{dyn} / \mathrm{cm}^{2}$. During this flow pulse, the maximum flow rate within the channels was $800 \mu \mathrm{L} / \mathrm{s}$ and the minimum flow rate was $0 \mu \mathrm{L} / \mathrm{s}$. Our chosen parameters for pressure and flow closely represented the data from initial physiological studies. Previous studies reported arteriole pressures of about $11 \mathrm{mmHg}$ [29]. Flow rates for the pulmonary vasculature vary tremendously due to physiological variation in the diameters of the arterioles and capillaries. We chose $800 \mu \mathrm{L} / \mathrm{s}$ because it is within other reported flow rates of $0.6 \mu \mathrm{L} / \mathrm{s}$ and $50,000 \mu \mathrm{L} / \mathrm{s}[30,31]$. 
A

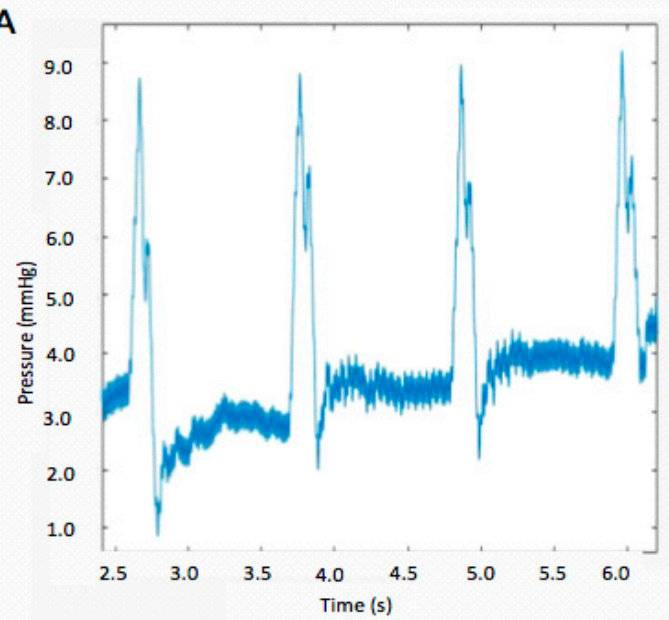

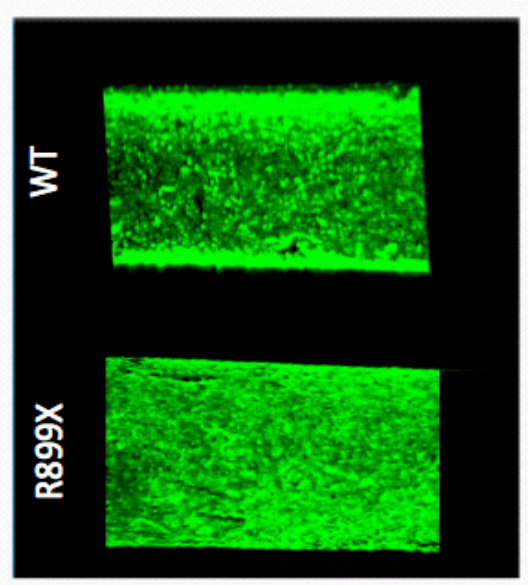

Figure 2. Validation of mechanical and cellular properties. (A) Sample waveform depicting the oscillatory pressure waves observed within the center of the channel. (B) WT and mutant Bmpr $2^{\text {R899X }}$ endothelial cell channels imaged at $5 \times$ with fluorescent calcein AM to observe the monolayer formed by the cells. Channels were imaged after perfusion to ensure that the endothelial monolayer remained intact after the flow experiments. Cells were removed from conditional immortalization and the transgene was activated though doxycycline.

\subsection{Artificial Pulmonary Arteriole Validation.}

Endothelium were formed by seeding the artificial arteriole with a total of 150,000 cells. After seeding, the cells lining the channels were allowed to proliferate until confluency. Channels were then perfused at an oscillatory flow rate of $800 \mu \mathrm{L} / \mathrm{s}$ with a pressure of $9 \mathrm{mmHg}$ for one second, followed by one second of relaxation (pump off). Seeded channels were imaged to verify that an artificial endothelium remained following $24 \mathrm{~h}$ of oscillatory flow (Figure 2). Only devices without any notable acellular patches or defects were used for additional experimentation.

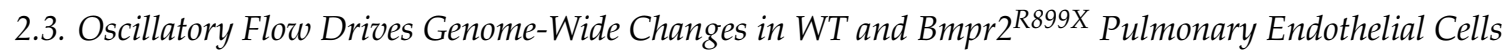

The molecular consequences of oscillatory flow on the $B m p r 2^{\mathrm{R} 899 \mathrm{X}}$ mutation were determined by performing RNA-Seq on an Illumina HiSeq system and measuring gene expression of both adult WT and Bmpr $2^{\text {R899X }}$ MPMVECs that were control immortalized with transgenes activated. After exposure to flow, the changes in gene expression within the mutant and WT cells as well as between perfusion conditions were dramatic, with 457 genes changed more than 0.4 log times the un-perfused condition.

Gene outcomes after exposure to flow were sorted into either a congruent or incongruent category (Figure 3). Congruent genes demonstrated similar directional changes in expression when exposed to flow, but are offset by different magnitudes in expression. A total of 248 genes were sorted into a congruent category. Of these congruent genes, 202 have functional annotation and 131 fell into statistically overrepresented gene ontology biological process groups. Figure 4 illustrates gene ontology groups by significance and number of genes.

The incongruent category is characterized by expression behavior that diverges when the cells are exposed to flow. For example, the introduction of flow may lead to an increase in expression in one group and a decrease in expression in another. A total of 209 genes were sorted into an incongruent category. Of these incongruent genes, 148 have functional annotation and 77 fell into statistically overrepresented gene ontology biological process groups (Figure 5).

Within the congruent category, the majority of genes were involved in the development of the circulatory system and other tissues. Other genes corresponded to the regulation of cell proliferation, cell death, and responses to external and mechanical stimuli. Similarly, many incongruent genes were involved in sensing external stimuli and the apoptotic process. Genes involved in cell adhesion were 
the most notably inconsistent gene ontology group when the congruent category was compared to the incongruent scenario. Both incongruent and congruent genes had ontologies correlating to mechanisms concerning response to external mechanical stimuli. In particular, the differences in cellular adhesion and cytoskeletal architecture were known to be different between Bmpr ${ }^{\mathrm{R} 899 \mathrm{X}}$ and WT cells.

\section{Congruent Changes}

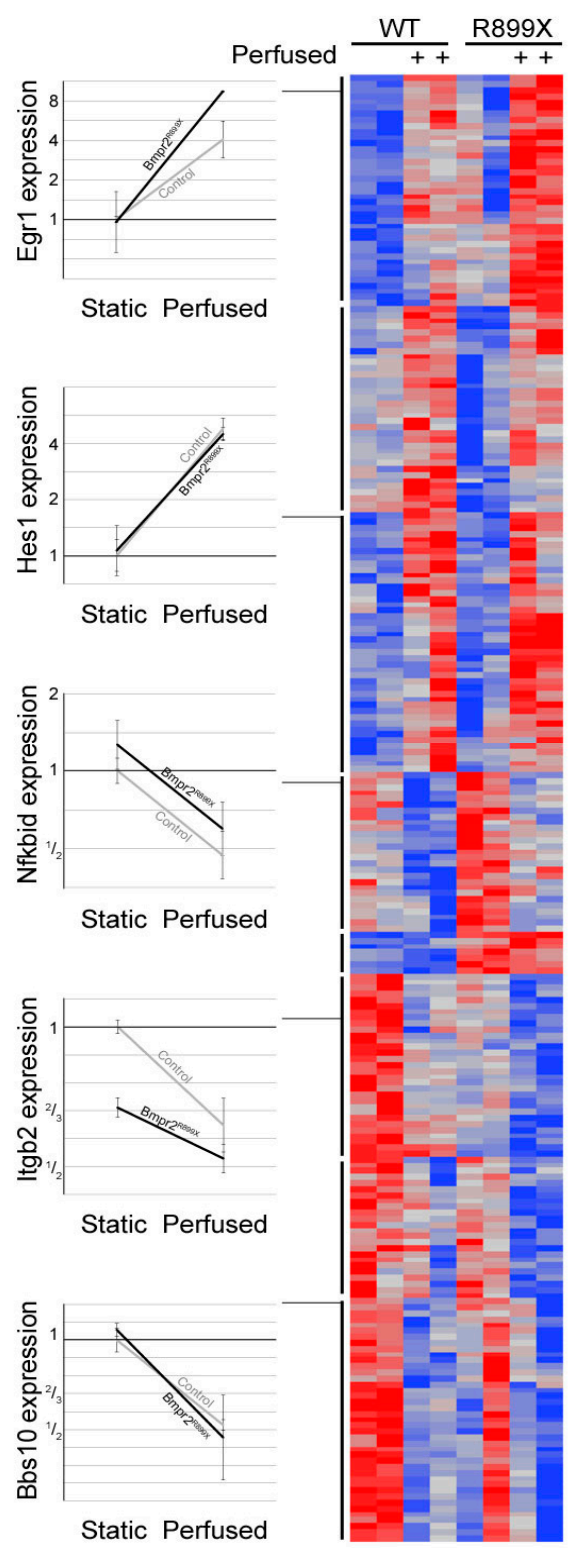

Incongruent Changes

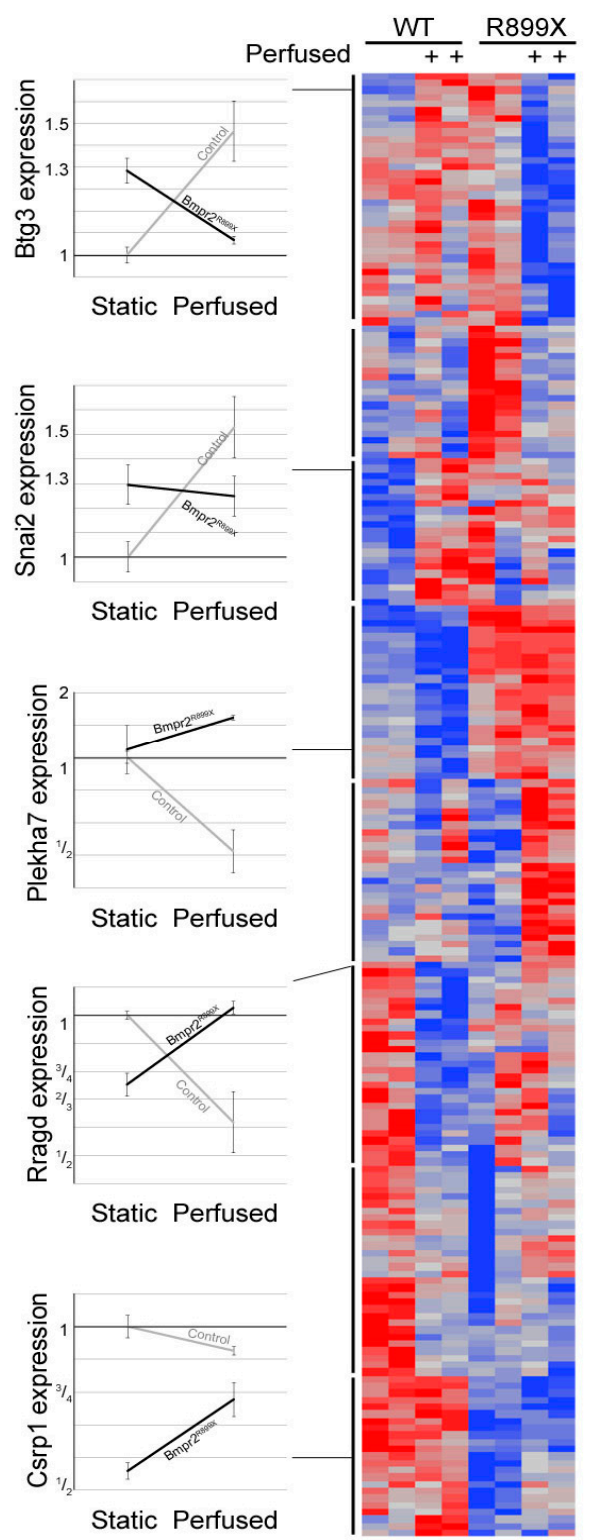

Figure 3. Congruent and incongruent heat map depiction of gene expression changes. Heat maps were separated by cell genotype (WT and Bmpr $2^{\mathrm{R} 899 \mathrm{X}}$ ) with flow (+) or without flow. Representative genes and corresponding expression changes were selected to illustrate change in expression seen within the congruent and incongruent maps. Congruent genes had similar directional changes to flow but were offset by the magnitude of expression. Incongruent genes had opposite directional responses to flow that result in different magnitude changes. The inclusion of flow led to notable gene expression changes in both the R899X and WT endothelial cell. Notable changes in gene expression were seen between the cell's genotype and flow conditions. 


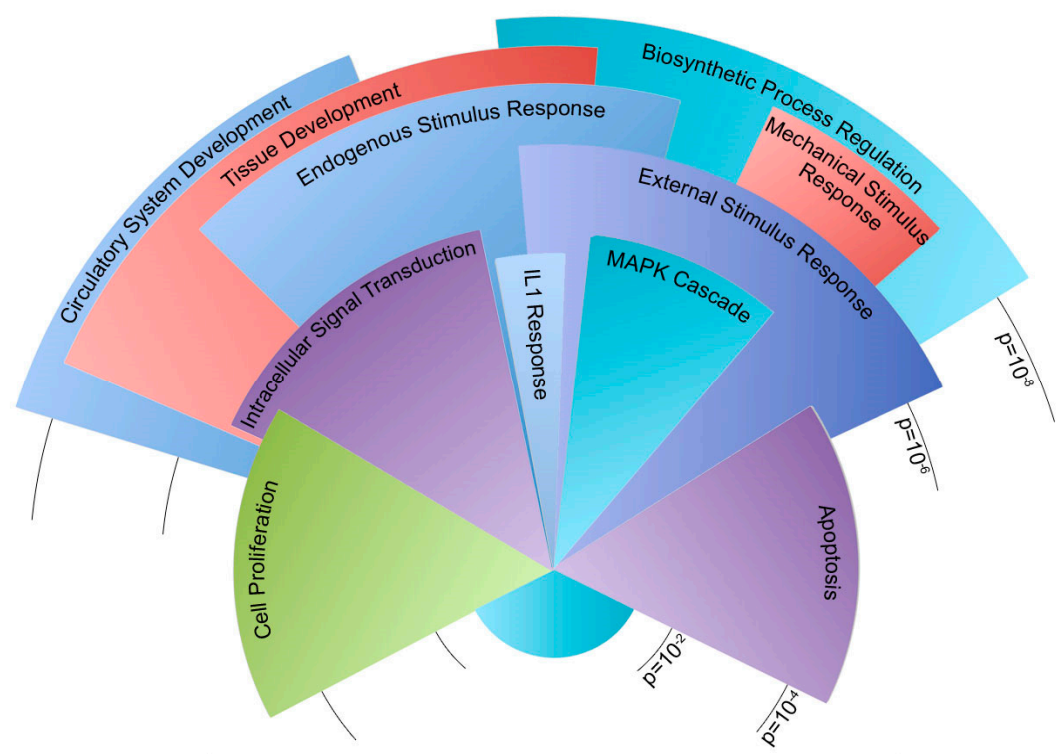

Figure 4. Congruent genes dysregulated in $B m p r 2^{\text {R899X }}$ endothelial cells after $24 \mathrm{~h}$ of perfusion. Pie chart shows relative number of genes in statistically dysregulated gene ontology groups. Arc length of the gene ontology groups corresponds to the number of genes present in each group. Radius length corresponds to significance, where the longest categories were significantly dysregulated at $\sim p<1 \times 10^{-8}$ and the shortest categories were dysregulated at $p<1 \times 10^{-3}$. Please see the Supplementary Materials for a table of these findings.

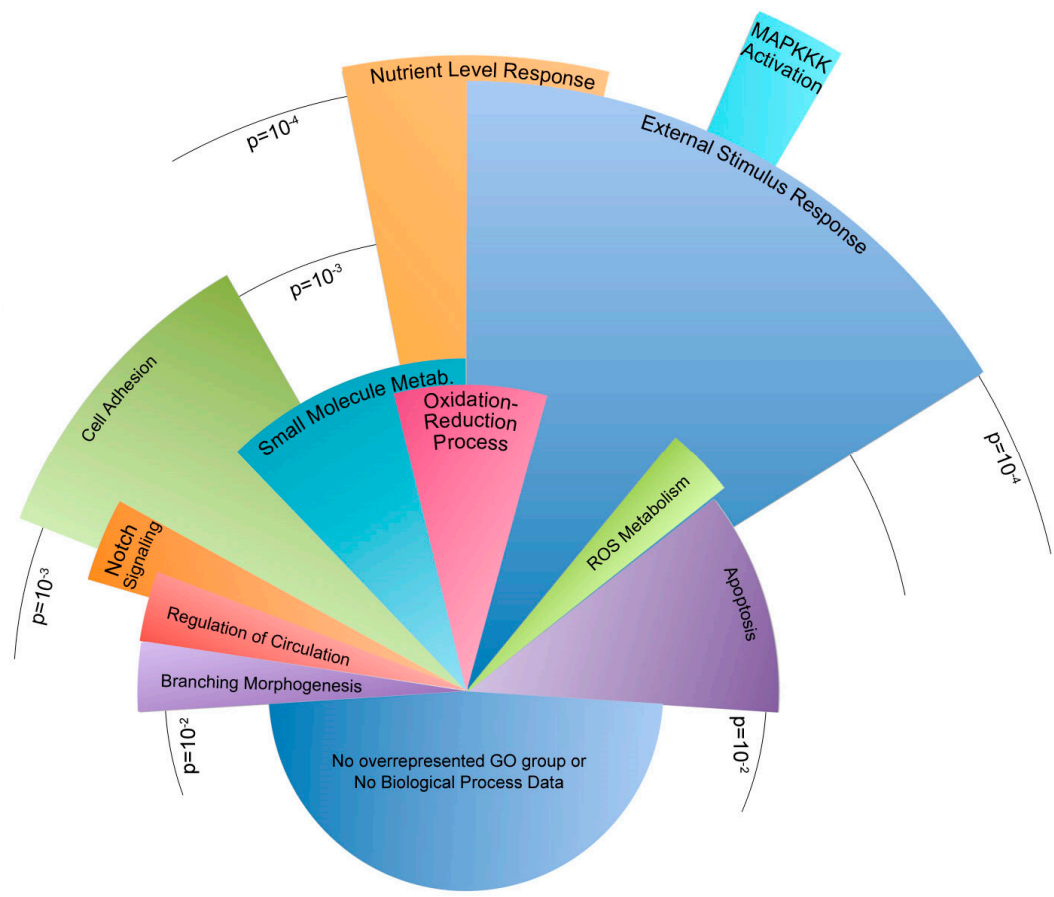

Figure 5. Incongruent genes dysregulated in Bmpr $2^{\mathrm{R} 899 \mathrm{X}}$ endothelial cells after $24 \mathrm{~h}$ of perfusion. Pie chart shows relative number of genes in statistically dysregulated gene ontology groups. Arc length of the gene ontology groups corresponds to the number of genes present in each group. Radius length corresponds to significance, where the longest categories were significantly dysregulated at $\sim p<1 \times 10^{-5}$ and the shortest categories were dysregulated at $p<1 \times 10^{-2}$. Please see the Supplementary Materials for a table of these findings. 


\subsection{Bmpr2 ${ }^{\text {R999X }}$ Pulmonary Endothelial Cells Do Not Change Morphology in Response to Flow}

Endothelial monolayers were imaged at three different time points $(t=0,1$, and $3 \mathrm{~h})$ to assess morphological response to flow within the artificial arteriole. As seen before [32-34], WT cells respond to flow by slowly elongating in the direction of shear. Conversely, the mutant $B m p r 2^{\mathrm{R} 899 \mathrm{X}}$ did not respond to flow and did not elongate after $3 \mathrm{~h}$ of exposure to perfusion (Figure 6).

This difference in alignment between $B m p r 2^{\mathrm{R} 899 \mathrm{X}}$ and WT was drastic after $3 \mathrm{~h}$ of perfusion $\left(p<1.0 \times 10^{-5}\right)$. WT cells responded to flow within an hour while the mutant cells showed no sign of elongation at $1 \mathrm{~h}\left(p<1.0 \times 10^{-4}\right)$. Before perfusion, both the WT and Bmpr $2^{\mathrm{R} 899 \mathrm{X}}$ cells had nearly indistinguishable cell morphologies $(p>0.05)$, with a similar alignment ratio of about 1.1 (measured by the ratio of cell's length in the flow direction divided by the length perpendicular to flow). The difference in morphology highlights the role that cellular adhesion and cytoskeletal genes may play in the mutant and WT cells when exposed to flow.
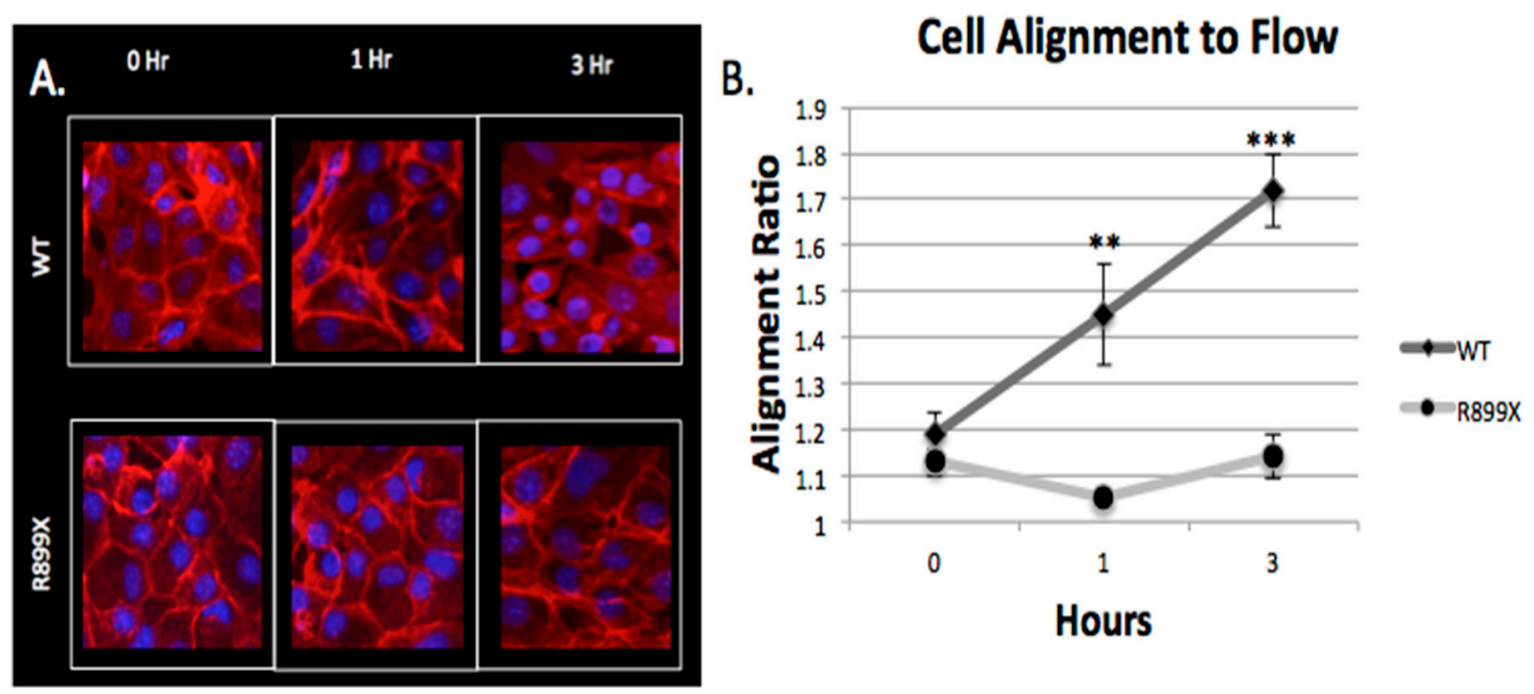

Figure 6. $B m p r 2^{\mathrm{R} 899 \mathrm{X}}$ endothelial cells do not align in the direction of flow. (A) Morphological differences were seen in the WT cells as the amount of perfusion time increases, whereas the Bmpr $2^{\text {R899X }}$ cells did not show evidence of elongation. Images were taken at $20 \times$. (B) Without perfusion, both Bmpr $2^{\mathrm{R} 899 \mathrm{X}}$ and WT endothelial cells showed no difference in cell morphology and alignment ratio $(p>0.05)$. After $1 \mathrm{~h}$ of perfusion, the WT cells started to align, but the Bmpr $2^{\mathrm{R} 899 \mathrm{X}}$ cells showed no evidence of aligning in the direction of flow $\left(p<1.0 \times 10^{-4}\right)$. The WT cells continued to elongate and increase their alignment ratio while the $B m p r 2^{\mathrm{R} 899 \mathrm{X}}$ cells maintained a nearly constant alignment ratio $\left(p<1.0 \times 10^{-5}\right) . N=3$ for all cells $\left(B m p r 2^{\text {R899X }}\right.$ and WT) in all time points.

\subsection{Bmpr2 ${ }^{\text {R899X }}$ Pulmonary Endothelial Cells Demonstrate Significant Barrier Dysfunction In-Vitro}

Channels and gels were imaged following either perfusion $(t=3 \mathrm{~h})$ or static conditions $(t=0 \mathrm{~h})$ to assess the barrier function of the Bmpr $2^{\mathrm{R} 899 \mathrm{X}}$ and WT endothelium lining the channels. The WT endothelial cells maintained barrier integrity when perfused with 10k FITC dextran in both perfused and static conditions with permeabilities of $1.65 \times 10^{-7}$ and $5.93 \times 10^{-8} \mathrm{~cm} / \mathrm{s}$, respectively. There was no significant difference between perfused and static WT channels $(p>0.05)$. As depicted in Figure 7A, little FITC dextran was seen leaking out of the WT channel and into the hydrogel. Unlike the WT experiments, the Bmpr $2^{\mathrm{R} 899 \mathrm{X}}$ endothelialized channels exhibited more FITC dextran leakage in both the perfusion and static conditions, with permeabilities of $1.51 \times 10^{-6}$ and $3.00 \times 10^{-6} \mathrm{~cm} / \mathrm{s}$, respectively. This increased permeability can also be seen in Figure 7A. Similarly to the WT channels, $B m p r 2^{\text {R899X }}$ channels had no significant differences in permeability in static or perfusion conditions $(p>0.05)$. A control channel without any endothelium had a greater amount of leakage than all seeded 
channels, regardless of the mutation. The control channel seen in Figure 7B has been outlined in order to see where it is located, as the fluorescence from the FITC dextran diffusion obfuscates the channel boundary. In both the perfusion and the static conditions, the WT channels were always less permeable than the Bmpr $2^{\mathrm{R} 899 \mathrm{X}}$ channels, with $p<0.05$ for both static and perfusion conditions (Figure 7C).
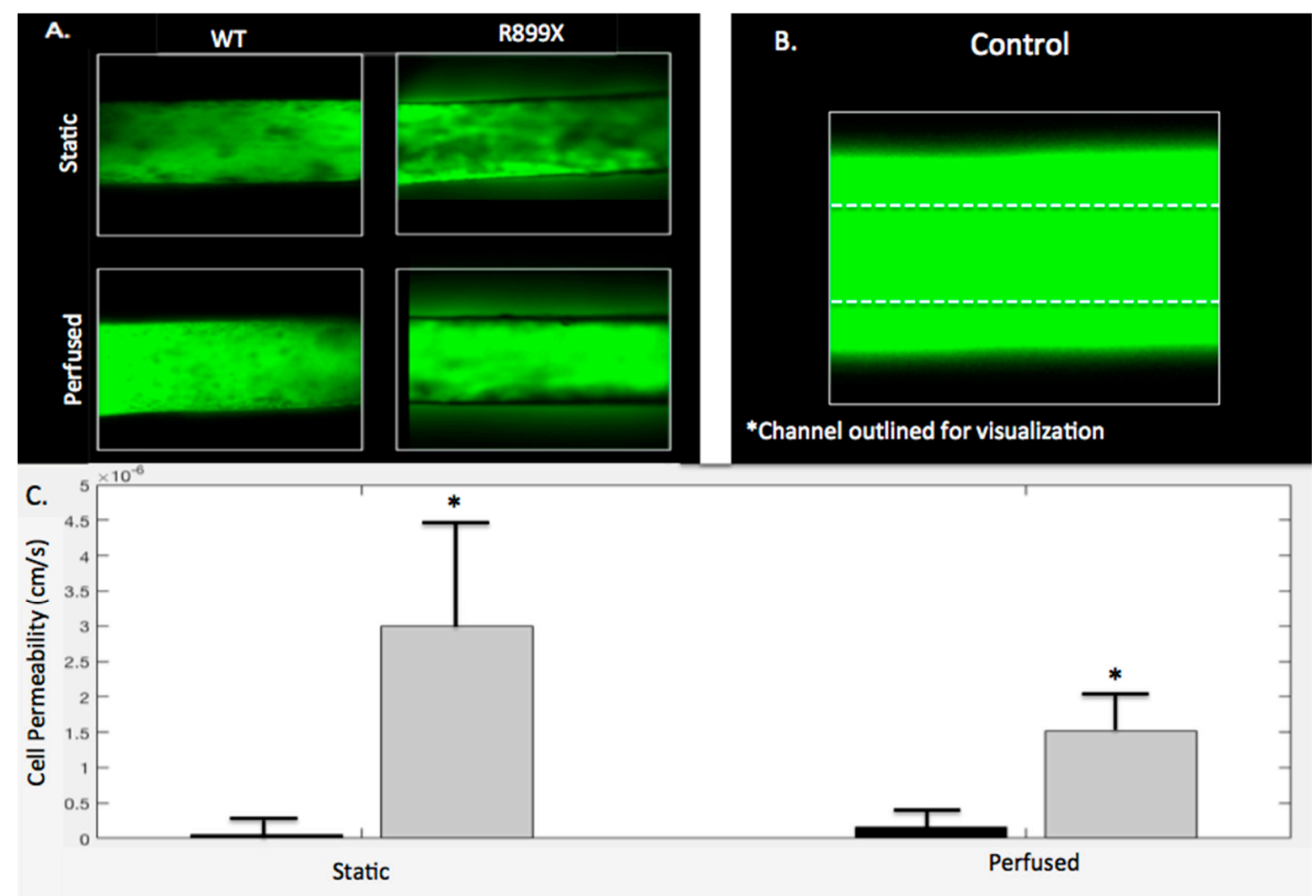

Figure 7. Bmpr $2^{\text {R899X }}$ MPMVECs have increased permeability compared to WT cells under both perfusion and static conditions. (A) Static and perfused WT and Bmpr $2^{\mathrm{R} 899 \mathrm{X}}$ channels were imaged at $5 \times$ magnification following one hour perfusion with FITC dextran. The channel diameter is $900 \mu \mathrm{m}(\mathbf{B})$ A control channel without cells was perfused with FITC dextran for comparison. Because of excessive fluorescence due to high permeability, the outline of the channel was added. (C) Permeabilities of the WT and Bmpr $2^{\text {R899X }}$ are plotted under both conditions to visualize magnitude differences in permeability between genotype. No statistical difference was seen between perfusion and static conditions in all genotypes $(p>0.05)$; however WT and Bmpr $2^{\mathrm{R} 899 \mathrm{X}}$ channels had significantly different permeabilities under both static and perfusion conditions $(p<0.05) . N=3$ for all cells (Bmpr $2^{\text {R899X }}$ and WT) in all conditions (static and perfused).

\section{Discussion}

Several groups have used microfluidic systems to model vascular shear to study the responses of endothelial cells to mechanical stimuli [35-38]. Inspired by these early characterizations of endothelial cells in the presence flow, we developed an artificial arteriole to study pulmonary vascular disease. When designing our platform, we sought to incorporate tunable parameters like shear stress, pressure, oscillatory flow, and crosslinking-controlled matrix stiffness so that a wider range of biological questions could be asked.

Before experimentation, all devices and platforms were tested for mechanical and cellular consistency prior to data collection (Figure 2). RNA-Seq from WT and Bmpr2 ${ }^{\text {R899X }}$ MPMVECs cultured under static and perfusion conditions demonstrated that many central pathways relevant to PAH etiology were altered in the mutant cells when exposed to flow (Figure 3). These findings were 
stratified into two categories: congruent or incongruent gene expression changes. The majority of significant genes discovered were in the congruent gene category. In this category, many of the gene pathways were involved in the development of the circulatory system, and may hint at the progression or penetrance of PAH (Figure 4). In most cases, the Bmpr $2^{\mathrm{R} 899 \mathrm{X}}$ cells demonstrated a greater level of gene expression when compared to the WT cells. The Bmpr $2^{\mathrm{R} 899 \mathrm{X}}$ cells tended to overrespond to many key molecular pathways responsible for endothelial maintenance and sensing, but these responses mirrored the up or down regulation patterns seen in the WT cells. The RNA Seq revealed that many of the pathways altered in response to pressure and flow may have relevance to BMPR2-associated PAH, and should be explored to further elucidate how mechanical stimuli may affect disease outcomes.

Gene expression in the incongruent category showed differing gene expression changes to many gene ontologies relevant to PAH. In many instances, the WT cells had up or down gene expression changes in response to flow, but the mutant $B m p r 2^{\mathrm{R} 899 \mathrm{X}}$ cells would often have a contradictory response. The most notable response was found in genes that regulate the cytoskeleton and regulate how cells respond to external stimuli (Figure 5). The deregulated cytoskeleton pathways have been observed before in traditional cell culture and align with the findings in our data [8,39-41]. The induction of mechanical stress (e.g., oscillatory pressure and flow) further exacerbated an already deregulated cytoskeletal profile and informs us that the mechanical environment in PAH may help drive disease.

Evidence of an altered response to flow and pressure was observed in the Bmpr $2^{\mathrm{R} 899 \mathrm{X}}$ cell's morphology when the channels were first perfused (Figure 6). Endothelial cells are known to respond to flow [32-34], but the aberrant alignment of the Bmpr $2^{\mathrm{R} 899 \mathrm{X}}$ cells may be correlated with the deregulated cytoskeletal and mechanical response pathways. The inability of the Bmpr $2^{\text {R899X }}$ mutant cells to adapt to flow conditions may explain many of the endothelial defects known to take place in PAH [42-44]. To our knowledge, this is the first report that the Bmpr $2^{\mathrm{R} 899 \mathrm{X}}$ endothelial cells do not align to flow, and may also be the first report of an endothelial cell that did not align in flow conditions.

Endothelial dysfunctional and permeability issues are a known hallmark of Bmpr $2^{\mathrm{R} 899 \mathrm{X}} \mathrm{PAH}$ [8]. Previous studies have observed that perfusion of Evan's Blue through the pulmonary vasculature of $B m p r 2^{\mathrm{R} 899 \mathrm{X}}$ mice results in observable leakage that is much higher than in control mice [8]. To recapitulate this behavior in our platform, we tested the permeability of $B m p r 2^{\mathrm{R} 899 \mathrm{X}}$ and WT endothelial MPMVECs cultured in our channels. Channels either experienced no flow or were perfused for $3 \mathrm{~h}$ to replicate the longest time point seen in the alignment study. After cells were exposed to oscillatory flow and perfused with dextran, fluorescence intensity values were measured within the channel, and within the region dextran diffused into the hydrogel. Permeability values were calculated for the Bmpr $2^{\text {R899X }}$ and WT cells in both perfused and static conditions. Figure 7 illustrates how the WT cells maintain a greater barrier to $10 \mathrm{k}$ dextran in both perfusion and static conditions when compared to the $B m p r 2^{R 899 X}$ cells $(p<0.05)$. The Bmpr $2^{\text {R899X }}$ cells are more permeable to both the WT cells in both the static and perfused condition, with the perfused condition not increasing the rate of permeability. The lack of significant differences in permeability under flow suggests that the pathologic barrier function in PAH may be independent of physiological pressure or flow.

The increased permeability of the Bmpr $2^{\mathrm{R} 899 \mathrm{X}}$ cells has been previously observed in vivo, but this is the first time similar increased permeability (as well as lack of cellular alignment) has been demonstrated in a 3D hydrogel culture model. No studies have looked at the impact of PAH's heritable $B m p r 2^{\mathrm{R} 899 \mathrm{X}}$ mutation and its changes in flow environments. These findings demonstrate how mechanical parameters often neglected in 2D cell culture yield important information needed to understand the pathology of PAH.

Our artificial arteriole recapitulated previously discovered deregulated gene expression pathways seen in 2D cell culture, and also re-created the increased permeability of Bmpr $2^{\mathrm{R} 899 \mathrm{X}}$ endothelium seen in mice. Our model advanced understanding on how flow and pressure within the pulmonary microvasculature may lead to several gene expression changes directly related to disease progression and development. The artificial arteriole also enabled the novel discovery that $B m p r 2^{\mathrm{R} 899 \mathrm{X}}$ cells do not 
elongate in the direction of flow, hinting at the possible correlation between deregulated sensing or cytoskeletal pathways and cellular adaptation to mechanical stress.

Future studies should aim to learn how the artificial arteriole could be used to model various stages of PAH. Pressure severity can be manipulated by using outlet tubing to control fluidic resistance within the channel. We do not know how the endothelium changes as the disease worsens, and this model may enable us to elucidate genotypic and phenotypic consequences as PAH changes. It is also important to learn how other ECM compositions in the model may influence endothelial behavior. Additionally, co-culture with other relevant cell types could enable novel studies of cellular interactions in this disease model and lead to greater understanding of other disease phenomena like inflammation.

\section{Materials and Methods}

\subsection{Device Construction}

A transparent PDMS (Sylgard 184, Dow Corning, Midland, MI, USA, mixed at 1:10 ratio) compartment was fabricated to house the artificial pulmonary vessel. This transparent mold was $12.5 \mathrm{~mm} \times 12.5 \mathrm{~mm}$ with a depth of $7 \mathrm{~mm}$. Holes were cut in the PDMS mold approximately $2 \mathrm{~mm}$ above the surface so that the artificial vessel was close to the surface of the PDMS, thereby facilitating high resolution imaging. If the channel were too close to the PDMS mold, anisotropic mechanical effects from the surrounding PDMS or ECM environment could be significant [45]. The ideal height of the fabricated vessel should be about $500 \mu \mathrm{m}$ from the surface of the mold [45]. A male luer lock to $1 / 16$ " adapter was fitted to a hole on one end of the PDMS mold (Cole Parmer, Vernon Hills, IL, USA). A solution of $10 \% w / v$ porcine gelatin (Sigma Aldrich, St. Louis, MO, USA) was dissolved in EGM2 media containing doxycline (Lonza, Alpharetta, GA, USA). A crosslinking enzyme, microbial transglutaminase (MTG) (Modernist Pantry, Eliot, ME, USA) was dissolved in 10\% $w / v$ PBS and mixed at $10 \% w / v$ with the gelatin to induce chemical crosslinking [46]. A 900- $\mu \mathrm{m}$ diameter steel rod served as a template to define the diameter of the artificial vessel. The rod was threaded through the PDMS holes and male luer adapters, and the MTG and gelatin solution was poured into the PDMS mold at $37^{\circ} \mathrm{C}$. Devices were covered and placed in $37^{\circ} \mathrm{C}$ incubator for $20 \mathrm{~min}$. After gelation, the rod was pulled from one side of the gelatin until completely removed. The hollow channels were then coated with $100 \mu \mathrm{g} / \mathrm{mL}$ collagen IV (Sigma Aldrich, St. Louis, MO, USA) and $100 \mu \mathrm{g} / \mathrm{mL}$ fibronectin (Sigma Aldrich, St. Louis, MO, USA) for $48 \mathrm{~h}$ before cell seeding. During coating, devices are kept submerged in media. See schematic representation of fabrication process in the Supplementary Materials.

Poiseuille's law was used to extract pressures at various lengths and radii from the channel geometry. Poiseuille's law defines the relationship below:

$$
\mathrm{Q}=\frac{\Delta \mathrm{P} \pi \mathrm{r}^{4}}{8 \mathrm{~L} \eta}
$$

After characterizing multiple diameter configurations, a $900-\mu \mathrm{m}$ channel was selected for experimentation. The $900-\mu \mathrm{m}$ channel had a shear stress of $98 \mathrm{dyn} / \mathrm{cm}^{2}$ and a shear rate of $11,178 \mathrm{~s}^{-1}$ The flow rate during a 100-ms pulse time was measured to be $800 \mu \mathrm{L} / \mathrm{s}$.

A DC peristaltic pump (Adafruit Industries, New York, NY, USA) was used to mimic the pulsatile nature of the heart. An Arduino microcontroller (Arduino, Turin, Italy) was used to power and control the pump duty cycle. The Arduino code provided pulses at $1 \mathrm{~Hz}$, or the standard human heart rate at 60 beats per minute. After the artificial arteriole was assembled, pressure waveforms were verified within the channel using a pressure sensitive catheter (Miller Instruments, Houston, TX, USA) at the center of the $900-\mu \mathrm{m}$ channel.

\subsection{Bmpr $2^{\text {R899X }}$ and WT Cells}

$B m p r 2^{\text {R899X }}$ cells were derived from Immortomouse X Rosa26-rtTA2 X TetO7- Bmpr $2^{\text {R899X }}$. The immortomouse contained a transgenic insertion of the SV40 large T antigen, tsA58, under the control 
of an interferon inducible promoter [47]. When the cells were grown at $33^{\circ} \mathrm{C}$ and the interferon added, the transgene was activated and the cells are immortalized. When the cells are moved to $37^{\circ} \mathrm{C}$, the transgene became inert. The immortalized cells proliferate as though they were immortalized at $33^{\circ} \mathrm{C}$, but revert to a normal mortal phenotype when cultured at $37^{\circ} \mathrm{C}$. The $B M P R 2$ mutation was induced by the addition of doxycycline to the media. The Immorto-BMPR 2 mutant pulmonary endothelial cells were harvested from mice as previously described [48].

\subsection{Cell Seeding}

$B m p r 2^{\mathrm{R} 899 \mathrm{X}}$ and WT cells were seeded at a density of 75,000 cells / device. The following day, the devices were seeded with another 75,000 cells/device. Cells were seeded directly into the channel by inserting a pipette tip into the luer lock. The devices were rotated every $30 \mathrm{~min}$ for two hours to encourage coating of the entire channel. All cell seeding took place in the immortalized condition $\left(33{ }^{\circ} \mathrm{C}\right.$ with appropriate media) with the BMPR2 mutation activated via doxycycline. $24 \mathrm{~h}$ prior to experimentation, conditional immortalization was turned off by moving the cells to $37^{\circ} \mathrm{C}$ and removing the interferon. Seeded channels were housed in wells while in the incubator. During the seeding process, the level of media in the wells was below the height of the channel to ensure all cells remained in the channel. After the cells were attached, the media level was increased to the height of the channel.

\subsection{Platform Set-Up}

Two perpendicular holes about $40 \mathrm{~mm}$ apart were drilled in medium polystyrene round containers (Ted Pella, Redding, CA, USA). Luer adapter fittings with lock nuts were inserted into the two drilled holes and secured with nylon panel lock nuts (Cole Parmer, Vernon Hills, IL, USA). The peristaltic pump was connected to the external conduits of the luer adapter. Within the container, one of the luer adapters was fitted with a $1.92 \mathrm{~mm}$ diameter tube (VWR, Randor, PA, USA) approximately $35 \mathrm{~mm}$ long that sat in the container. The other luer adapter was fitted with the same tubing but with a female luer lock to $1 / 16^{\prime \prime}$ adapter fitted to the end. Prior to experimentation, the perfusion setup was submerged in bleach for $24 \mathrm{~h}$ and then 100\% ethanol for $48 \mathrm{~h}$. Immediately before use, the containers were aspirated of liquid, dried, and rinsed with PBS. The peristaltic pump was used to perfuse $100 \mathrm{~mL}$ of $100 \%$ ethanol and then $100 \mathrm{~mL}$ of PBS immediately before use. The containers were filled with $20 \mathrm{~mL}$ of media containing doxycycline (without immortalized conditions) via perfusion using the peristaltic pump until no air was left in the tubing. Fully endothelialized channels were attached to the female luer adapter within the container. The containers and the channels were placed in an incubator (Hera Cell 150) and connected to the microcontroller and then perfusion was initiated. See Supplementary Materials for images.

\subsection{Assessment of Artificial Lumen}

$24 \mathrm{~h}$ after the second seeding, channels were perfused and then assessed for confluent monolayers around the entire cylinder. Channels were stained with calcein AM stain (Life Technologies, Carlsbad, CA, USA). A Zeiss LSM 710 Confocal Microscope was used to determine whether the cells formed a confluent lining on the channels. Channels that were not confluent were disconnected from perfusion and monitored until cells had proliferated such that confluency was achieved.

\subsection{RNA Sequencing}

Channels were perfused for $24 \mathrm{~h}$. Each array consisted of two channels per condition (Bmpr2 ${ }^{\text {R899X }}$ and WT and perfused or static). RNA-Seq was performed on an Illumina HiSeq (San Diego, CA, USA) system with a directional mRNA library prep, SR-50, with 30 million reads. RNA aligning was performed with TopHat (Toronto, ON, Canada) to verify consensus genome sequence using ultra high-throughput short read aligner Bowtie2. Gene ontology analyses were performed with WebGestalt (Houston, TX, USA) as previously reported $[49,50]$. 


\subsection{Endothelial Alignment}

The channels were perfused with media for 0,1 , and $3 \mathrm{~h}$. Cells were immediately fixed and permeabilized within the channel. Cells were stained with phalloidin and DAPI and imaged with a Zeiss LSM 710 Confocal Microscope. Three devices were imaged per condition and a minimum of three images were taken per device. Alignment was quantified in ImageJ (Bethesda, MD, USA) by measuring the cellular length in the direction of flow and the cellular width perpendicular to flow. A ratio of the length to the width was calculated to quantify the elongation of the cell in response to flow.

\subsection{Barrier Function}

The channels were perfused with media for 0 and $3 \mathrm{~h}$. Cells were perfused $(30 \mu \mathrm{L} / \mathrm{min})$ for $1 \mathrm{~h}$ with FITC-dextran ( $5 \mathrm{mg} / \mathrm{mL}, \mathrm{M}_{\mathrm{W}}=5,000$, Invitrogen, Carlsbad, CA, USA) and imaged every thirty seconds. The fluorescence signal of the permeabilized FITC-dextran was quantified in ImageJ and Matlab (Natick, MA, USA) (see code in Supplementary Materials). Intensity values were manually extracted from ImageJ in order to compensate for unanticipated channel movement. The diffusion coefficient of dextran within the gelatin was calculated before experimentation [51-55].

\subsection{Statistical Analysis}

Statistics were performed using a one or two factor ANOVA $(+/-B M P R 2$ mutation and + / perfusion) with a Fisher's exact post hoc test for comparisons between groups. P-values less than 0.05 were considered significant, but $p$ values $p<0.1$ were still used in the RNA seq analysis. Statistics were performed in R Studio (Boston, MA, USA).

Supplementary Materials: Supplementary materials can be found at http:/ / www.mdpi.com/1422-0067/19/9/ 2561/s1.

Author Contributions: Conceptualization, R.W.D.; L.M.B., and J.D.W.; Methodology, R.W.D.; S.F.; Software, R.W.D.; S.F..; Validation, R.W.D.; S.F.; Formal Analysis, R.W.D.; H-n.S.; J.R.P., V.A.; Investigation, R.W.D.; Resources, L.M.B.; J.D.W.; Data Curation, R.W.D.; H-n.S.; J.R.P.; Writing-Original Draft Preparation, R.W.D.; J.D.W.; Writing-Review \& Editing, R.W.D.; J.D.W.; L.M.B.; Visualization R.D.W.; S.F.; Supervision, J.D.W.; L.M.B.; Project Administration, S.F.; J.D.W.; L.M.B.; Funding Acquisition, J.D.W; L.M.B.

Funding: This work was supported by the following NIH grants: R01HL095797 and NIH R00EB013630 and NSF grant: NSF 1506717; RWD was supported as an NSF Graduate Research Fellow.

Acknowledgments: We are thankful for the administrative work done by Santhi Gladson and to Thomas Blackwell for supplying the cells. We also thank Brian O'Grady for tutorials in data analysis.

Conflicts of Interest: The authors declare no conflict of interest

\section{Abbreviations}

BMPR2 Bone Morphogenetic Protein Type II Receptor

MPMVEC Murine Pulmonary Microvascular Endothelial Cells

MTG Microbial transglutaminase

PAH Pulmonary Arterial Hypertension

WT Wild type

\section{References}

1. Cool, C.D.; Stewart, J.S. Three-dimensional reconstruction of pulmonary arteries in plexiform pulmonary hypertension using cell-specific markers. Evidence for a dynamic and heterogeneous process of pulmonary endothelial cell growth. Am. J. Pathol. 1999, 155, 411-419. [CrossRef]

2. Austin, E.D.; Loyd, J.E. The genetics of pulmonary arterial hypertension. Circ. Res. 2014, 115, $189-202$. [CrossRef] [PubMed]

3. Austin, E.D.; West, J. Molecular Medicine of Pulmonary Arterial Hypertension: From Population Genetics to Precision Medicine and Gene Editing. Am. J. Resp. Crit. Care Med. 2016, 195, 23-31. [CrossRef] [PubMed] 
4. De Jesus Perez, V.A. Molecular pathogenesis and current pathology of pulmonary hypertension. Heart Fail Rev. 2016, 21, 239-257. [CrossRef] [PubMed]

5. Humbert, M.; Sitbon, O. Survival in patients with idiopathic, familial, and anorexigen-associated pulmonary arterial hypertension in the modern management era. Circulation 2010, 122, 156-163. [CrossRef] [PubMed]

6. Rubin, L.J. Pulmonary arterial hypertension. Proc. Am. Thorac. Soc. 2006, 3, 111-115. [CrossRef] [PubMed]

7. Runo, J.R.; Loyd, J.E. Primary pulmonary hypertension. Lancet 2003, 361, 1533-1544. [CrossRef]

8. Johnson, J.A.; Hemnes, A.R. Cytoskeletal defects in Bmpr2-associated pulmonary arterial hypertension. Am. J. Physiol. Lung Cell Mol. Physiol. 2012, 302, L474-L484. [CrossRef] [PubMed]

9. Geraci, M.W.; Moore, M. Gene expression patterns in the lungs of patients with primary pulmonary hypertension: A gene microarray analysis. Circ. Res. 2001, 88, 555-562. [CrossRef] [PubMed]

10. Rajkumar, R.; Konishi, K. Genomewide RNA expression profiling in lung identifies distinct signatures in idiopathic pulmonary arterial hypertension and secondary pulmonary hypertension. Am. J. Physiol. Heart Circ. Physiol. 2010, 298, H1235-H1248. [CrossRef] [PubMed]

11. Bayless, K.J.; Davis, G.E. The Cdc42 and Rac1 GTPases are required for capillary lumen formation in three-dimensional extracellular matrices. J. Cell Sci. 2002, 115, 1123-1136. [PubMed]

12. Connolly, J.O.; Simpson, N. Rac regulates endothelial morphogenesis and capillary assembly. Mol. Biol. Cell 2002, 13, 2193-2557. [CrossRef] [PubMed]

13. Koh, W.; Mahan, R.D. Cdc42-and Rac1-mediated endothelial lumen formation requires Pak2, Pak4 and Par3, and PKC-dependent signaling. J. Cell Sci. 2008, 121, 989-1001. [CrossRef] [PubMed]

14. Lovren, F.; Pan, Y. Angiotensin converting enzyme-2 confers endothelial protection and attenuates atherosclerosis. Am. J. Physiol. Heart Circ. Physiol. 2008, 295, H1377-H1384. [CrossRef] [PubMed]

15. Resnick, N.; Gimbrone, M.A. Hemodynamic forces are complex regulators of endothelial gene expression. FASEB J. 1995, 9, 874-882. [CrossRef] [PubMed]

16. Chen, B.P.; Li, Y.S. DNA microarray analysis of gene expression in endothelial cells in response to 24-h shear stress. Physiol. Genom. 2001, 7, 55-63. [CrossRef] [PubMed]

17. Blank, R.H.; Muller, W.H. Changes in pulmonary vascular lesions after restoring normal pulmonary artery pressure. Surg. Forum. 1958, 9, 356-359. [PubMed]

18. Dammann, J.F.; McEachen, J.A. The regression of pulmonary vascular disease after the creation of pulmonary stenosis. J. Thorac. Cardiovasc. Surg. 1961, 42, 722-734. [PubMed]

19. Ferguson, D.J.; Berkas, E.M. Process of healing in experimental pulmonary arteriosclerosis. Proc. Soc. Exp. Biol. Med. 1955, 89, 492-494. [CrossRef] [PubMed]

20. Heath, D.; Helmholz, H.F. Relation between structural change in the small pulmonary arteries and the immediate reversibility of pulmonary hypertension following closure of ventricular and atrial septal defects. Circulation 1958, 18, 1167-1174. [CrossRef] [PubMed]

21. Geer, J.C.; Glass, B.A. The Morphogenesis and Reversibility of Experimental Hyperkinetic Pulmonary Vascular Lesions in the Dog. Exp. Mol. Pathol. 1965, 4, 399-415. [CrossRef]

22. Bertero, T.; Oldham, W.M. Vascular stiffness mechanoactivates YAP/TAZ-dependent glutaminolysis to drive pulmonary hypertension. J. Clin. Investig. 2016, 126, 3313-3335. [CrossRef] [PubMed]

23. Scott, D.; Tan, Y. High pulsatility flow stimulates smooth muscle cell hypertrophy and contractile protein expression. Am. J. Physiol. Lung Cell Mol. Physiol. 2013, 304, L70-L81. [CrossRef] [PubMed]

24. Wedgewood, S.; Lakshminrusimha, S. Cyclic stretch stimulates mitochondrial reactive oxygen species and Nox4 signaling in pulmonary artery smooth muscle cells. Am. J. Physiol. Lung Cell Mol. Physiol. 2015, 309, L196-L203. [CrossRef] [PubMed]

25. Davies, P.F. Flow-mediated endothelial mechanotransduction. Physiol. Rev. 1995, 75, 519-560. [CrossRef] [PubMed]

26. Ingber, D.E. Mechanical signaling and the cellular response to extracellular matrix in angiogenesis and cardiovascular physiology. Circ. Res. 2002, 91, 877-887. [CrossRef] [PubMed]

27. Intengan, H.D.; Schiffrin, E.L. Structure and mechanical properties of resistance arteries in hypertension: Role of adhesion molecules and extracellular matrix determinants. Hypertension 2000, 36, 312-318. [CrossRef] [PubMed]

28. Lee, K.M.; Tsai, K.Y. Extracellular matrix and pulmonary hypertension: Control of vascular smooth muscle cell contractility. Am. J. Physiol. Heart Circ. Physiol. 1998, 274, H76-H82. [CrossRef] 
29. Negrini, D.; Gonano, C. Microvascular pressure profile in intact in situ lung. J. Appl. Physiol. 1992, 72, 332-339. [CrossRef] [PubMed]

30. De Lee, G.J.; DuBois, A.B. Pulmonary capillary blood flow in man. J. Clin. Investig. 1955, 34, 1380-1390. [CrossRef] [PubMed]

31. Haber, S.; Clark, A. Blood Flow in Capillaries of the Human Lung. J. Biomech. Eng. 2013, 135, 101006. [CrossRef] [PubMed]

32. Levesque, M.J.; Nerem, R.M. The elongation and orientation of cultured endothelial cells in response to shear stress. J. Biomech. Eng. 1985, 107, 341-347. [CrossRef] [PubMed]

33. Dewey, C.F.; Bussolari, S.R. The dynamic response of vascular endothelial cells to fluid shear stress. J. Biomech. Eng. 1981, 103, 177-185. [CrossRef] [PubMed]

34. Tzima, E.; del Pozo, M.A. Activation of integrins in endothelial cells by fluid shear stress mediates Rho-dependent cytoskeletal alignment. EMBO J. 2001, 20, 4639-4647. [CrossRef] [PubMed]

35. Gimbrone, M.A.; Topper, J.N. Endothelial dysfunction, hemodynamic forces, and atherogenesis. Ann. N. Y. Acad. Sci. 2000, 902, 230-240. [CrossRef] [PubMed]

36. Blackman, B.R.; Guillermo, G.C. A new in vitro model to evaluate differential responses of endothelial cells to simulated arterial shear stress waveforms. J. Biomech. Eng. 2002, 124, 397-407. [CrossRef] [PubMed]

37. Balcells, M.; Suárez, M.F. Cells in fluidic environments are sensitive to flow frequency. J. Cell Physiol. 2005, 204, 329-335. [CrossRef] [PubMed]

38. Li, M.; Scott, D.E. High pulsatility flow induces adhesion molecule and cytokine mRNA expression in distal pulmonary artery endothelial cells. Ann. Biomed. Eng. 2009, 37, 1082-1092. [CrossRef] [PubMed]

39. Foletta, V.C.; Lim, M.A. Direct signaling by the BMP type II receptor via the cytoskeletal regulator LIMK1. J. Cell. Biol. 2003, 162, 1089-1098. [CrossRef] [PubMed]

40. Machado, R.D.; Rudarakanchana, N. Functional interaction between BMPR-II and Tctex-1, a light chain of Dynein, is isoform-specific and disrupted by mutations underlying primary pulmonary hypertension. Hum. Mol. Genet. 2003, 12, 3277-3286. [CrossRef] [PubMed]

41. Wong, W.K.; Knowles, J.A. Bone morphogenetic protein receptor type II C-terminus interacts with c-Src: Implication for a role in pulmonary arterial hypertension. Am. J. Respir. Cell Mol. Biol. 2005, 33, 438-446. [CrossRef] [PubMed]

42. Budhiraja, R.; Rubin, M.T. Endothelial dysfunction in pulmonary hypertension. Circulation 2004, 109, $159-165$. [CrossRef] [PubMed]

43. Humbert, M.; Morrell, N.W. Cellular and molecular pathobiology of pulmonary arterial hypertension. J. Am. Coll. Cardiol. 2004, 43, 13S-24S. [CrossRef] [PubMed]

44. Morrell, N.W.; Adnot, S. Cellular and molecular basis of pulmonary arterial hypertension. J. Am. Coll. Cardiol. 2009, 54, 20S-31S. [CrossRef] [PubMed]

45. Lo, C.M.; Wang, H.B. Cell movement is guided by the rigidity of the substrate. Biophys. J. 2000, 79, $144-152$. [CrossRef]

46. Bellan, L.M.; Pearsall, M. A 3D interconnected microchannel network formed in gelatin by sacrificial shellac microfibers. Adv. Mater. 2012, 24, 5187-5191. [CrossRef] [PubMed]

47. Jat, P.S.; Noble, M.D. Direct derivation of conditionally immortal cell lines from an $\mathrm{H}-2 \mathrm{~Kb}$-tsA58 transgenic mouse. Proc. Natl. Acad. Sci. USA 1991, 88, 5096-5100. [CrossRef] [PubMed]

48. Pozzi, A.; Moberg, P.E. Elevated matrix metalloprotease and angiostatin levels in integrin alpha 1 knockout mice cause reduced tumor vascularization. Proc. Natl. Acad. Sci. USA 2000, 97, 2202-2207. [CrossRef] [PubMed]

49. Wang, J.; Duncan, D. WEB-based gene set analysis toolkit (WebGestalt): Update 2013. Nucle. Aci. Res. 2013, 41, W77-W83. [CrossRef] [PubMed]

50. Zhang, B.; Stefan, K. WebGestalt: An integrated system for exploring gene sets in various biological contexts. Nucleic Acids Res. 2005, 33, W741-W748. [CrossRef] [PubMed]

51. Arrio-Dupont, M.; Cribier, S. Diffusion of fluorescently labeled macromolecules in cultured muscle cells. Biophys. J. 1996, 70, 2327-2332. [CrossRef]

52. Braeckmans, K.; Peeters, L. Three-dimensional fluorescence recovery after photobleaching with the confocal scanning laser microscope. Biophys. J. 2003, 85, P2240-P2252. [CrossRef]

53. Kang, M.; Day, C.A. Simplified equation to extract diffusion coefficients from confocal FRAP data. Traffic 2012, 13, 1589-1600. [CrossRef] [PubMed] 
54. Schindelin, J.; Arganda-Carreras, I. Fiji: An open-source platform for biological-image analysis. Nat. Methods 2012, 9, 676-682. [CrossRef] [PubMed]

55. Schneider, C.A.; Rasband, W.S. NIH Image to ImageJ: 25 years of image analysis. Nat. Methods 2012, 9, 671-675. [CrossRef] [PubMed] 